\title{
Prestige of an influencer and perceptions of power*
}

\author{
BARRY R. SCHLENKER \\ and PATRICIA A. SCHLENKER \\ University of Florida, Gainesville, Fla. 32601
}

Twenty male and 30 female Ss rated the amount of influence possessed by hypothetical persons described by various adjectives. Influencers were rated on two response dimensions, when employing threats as an influence mode and when employing persuasion as an influence mode. Influencers were described as either high (wealthy) or low (poor) in capability to influence, and as having either accommodative or exploitative influence intentions. When threats were employed as the influence mode, Ss perceived the influencer to be more powerful when described as wealthy rather than poor, and exploitative rather than accommodative. When persuasion was employed as the influence mode, Ss perceived the influencer to be more powerful when described as wealthy rather than poor, and accommodative rather than exploitative. The adjective descriptions of the hypothetical influencers were combined by $S s$ in a simple linear fashion on both dimensions in determining their impressions of influence.

The wealth or material possessions of a potential source of social influence and his intentions to use his resources to benefit or harm a target person are central concepts in the area of social power. In an analysis of international relations, Singer (1958) has considered threat perception to be a function of two factors: the amount of resources at the disposal of the source and the perceived willingness of the source to use those resources for purposes of influence. Singer assumed that capability and intentions combine multiplicatively to determine the extent of perceived threat and power of the influencer. Thus, if a nation has either few resources or seldom expresses its desire to coerce other nations, it would not be perceived as a threat. If the value of either variable remains low while the other increases, a threat still will not be perceived. Only when both intent and capability to harm coexist will threat perception occur. Pruitt (1965) has proposed a slightly different relationship between capability, intentions, and perceptions of threat. He hypothesized that nations will be predisposed to infer malevolent and exploitative intentions on the part of another nation whenever evidence of the latter's capability to do harm is present and information about intentions is ambiguous or absent. Thus, while Pruitt assumed a multiplicative relationship between intentions and capability in determining threat perception, threat perception will occur in an ambiguous situation when either high capability alone or high capability plus exploitative intentions exist.

*Sponsored by Marvin E. Shaw, who takes full editorial responsibility for its contents.
Tedeschi, Bonoma, \& Schlenker (1972) have discussed the effects of capability and intentions on interpersonal interactions. The combination of capability and intentions determines an individual's prestige in a social setting. Capability was defined as the disposable material resources possessed by an individual which could be employed for purposes of rewarding or punishing prospective targets. Intentions were conceptualized along a dimension anchored at one end by accommodativeness and at the other by exploitativeness. Following Singer, Tedeschi et al hypothesized that information concerning the source's capability and intentions is combined by onlookers in a multiplicative fashion to determine the prestige and perceived power of a prospective influencer. Irrespective of the influence mode employed by the source, it was hypothesized that capability would be positively related to the perceived power of the source (holding the scale value of intentions constant at some nonzero value). The scaling of the intentions dimension was hypothesized to depend upon the type of influence employed by the source. When positive influence modes, e.g., persuasion or reward power, are employed, perceptions of power would be positively related to the source's perceived accommodativeness (holding the scale value of capability constant at some nonzero value). However, when negative modes of influence, e.g., coercion, are employed, perceptions of power would be positively related to the source's perceived exploitativeness (again holding the scale value of capability constant at some nonzero value). Thus, a wealthy and exploitative individual would be perceived as having greater power than a wealthy and accommodative individual if he used coercion as an influence tactic, while the latter individual would be perceived as having greater power than the former if he used persuasion as an influence tactic. The literature on attitude change supports the positive relationship between a source's accommodative intentions and compliance to persuasion attempts (cf. McGuire, 1969), although it has relatively little to add about how the capability and intentions dimensions combine to determine perceptions of power.

The present experiment examined the relationship between the capability and intentions dimensions on Ss' perceptions of the power of hypothetical sources of influence. The task involved a person perception situation which was first introduced by Asch (1946) and employed in systematic studies of information integration in impression formation by Anderson (cf. $1968,1970,1973)$. Ss were asked to rate the amount of power possessed by individuals described by various adjective traits. The adjectives chosen for stimulus presentation were selected to represent the end points of the intentions and capability dimensions and included 
Table 1

Mean Judgments of Perceived Influence for Each of the Prestige Combinations

\begin{tabular}{|c|c|c|c|c|}
\hline \multirow[b]{2}{*}{$\begin{array}{l}\text { Response } \\
\text { Dimension }\end{array}$} & \multicolumn{4}{|c|}{ Prestige Combinations } \\
\hline & $\begin{array}{l}\text { Wealthy/ } \\
\text { Accom- } \\
\text { modative }\end{array}$ & $\begin{array}{l}\text { Wealthy/ } \\
\text { Exploita- } \\
\text { tive }\end{array}$ & $\begin{array}{c}\text { Poor/ } \\
\text { Accom- } \\
\text { modative }\end{array}$ & $\begin{array}{l}\text { Poor/ } \\
\text { Exploita- } \\
\text { tive }\end{array}$ \\
\hline Persuasion & 15.9 & 13.6 & 9.6 & 6.7 \\
\hline Threats & 14.7 & 17.1 & 6.7 & 8.6 \\
\hline
\end{tabular}

accommodative-exploitative and wealthy-poor, respectively. Each $\mathrm{S}$ was given all four combinations of adjectives as well as each adjective alone, and asked to rate each person described by the traits when coercion was employed as the influence mode and when persuasion was employed as the influence mode.

The manner of Ss' integration of the prestige-related stimuli in determining perceptions of influence was assessed via functional measurement (Anderson, 1970, 1971, 1973). Functional measurement relies on the use of an information integration task and provides data on the manner of S's combination of stimuli in determining an overall impression. The technique has been employed to assess the applicability of averaging, subtracting, and multiplying models of information integration. The four adjectives form a row-by-column factorial design, with each cell of the design representing one person description based on the combination of two traits, one trait from each of the two prestige dimensions. If stimuli are combined in a simple linear manner (e.g., an additive or averaging model) in determining perceptions of the influencers, then no interaction between dimensions should be revealed in a 2 by 2 repeated measures analysis of variance. However, if the stimuli are combined in a nonadditive or multiplicative manner in determining perceptions, an interaction between dimensions should be obtained (cf. Anderson, 1970).

It was hypothesized that: (1) a person would be perceived as more influential when described as wealthy rather than poor irrespective of the influence mode employed; (2) a person would be perceived as a more influential persuader when described as accommodative rather than exploitative; (3) a person would be perceived as a more influential threatener when described as exploitative rather than accomodative.

\section{METHOD \\ Subjects}

Twenty male and 30 female students at the State University of New York at Albany participated in partial fulfillment of an introductory psychology course requirement.

\section{Procedure}

Ss were told that the experiment involved impression formation and were presented with a booklet which described the task and contained the adjective combinations. The first page of the booklet informed Ss that they were to imagine a person described by each of the adjective pairs presented on the pages which followed and then rate that person on the dimension which appeared at the top of the page. For half the Ss, the next page of the booklet instructed them to "Rate the amount of persuasiveness that you feel each person described by each set of two adjectives below would have over the average individual; that is, rate each person's ability to use rational appeals to cause other people to do as he wants them to do. Record your estimate of the persuasiveness of each person in the answer blank next to each adjective set. Your estimate should be whole numbers from 1 to 20 where 1 indicates that the person would have no chance of getting other people to do anything he wants them to do and 20 indicates that the person would be able to get other people to do everything he wants them to do." The next page of the booklet asked Ss to "Rate the amount of influence that you feel each person described by each set of two adjectives below would have over the average individual through the use of threats; that is, through the use of statements which implicitly or explicitly demand that another person does as he wants or else he will harm them." Ratings of perceived influence again were made by placing a number from 1 to 20 , inclusive, in the blank next to each adjective description. The other half of the Ss received the same test pages with the order of presentation reversed. Ss were instructed to work on one page at a time and not to turn a page until they had completed the one on which they were working and not to go back once having turned the page.

Four adjectives were chosen for presentation which seemed to best describe the end points of the intentions and capability dimensions: accommodative-exploitative and wealthy-poor, respectively. Four adjective descriptions of sources of influence were formed by the combination of the words: wealthy-accommodative (W-A), wealthy-exploitative (W-E), poor-accommodative (P-A), and poor-exploitative (P-E). Each of the four adjective pairs was presented underneath the description of the rating dimension on each page. The adjectives were presented in the order: W-A, P-E, W-E, P-A.

The last two pages of the booklet contained the four adjectives presented singly under each of the rating dimensions. Ss were instructed to rate a person described by each of the single adjectives when each person was using threats and when he was using persuasion. Order of presentation of these two pages also was counterbalanced.

\section{RESULTS}

Neither sex of Ss nor order of presentation of the response dimensions (i.e., persuasion first or threats first) affected ratings of perceived influence, so the following analyses will be presented with these variables collapsed. Table 1 presents Ss' mean judgments of the perceived influence for each combination for both the persuasion dimension and the threat dimension.

A 2 by 2 analysis with repeated measures was performed on ratings of influence for each of the dimensions. Analysis of Ss' ratings of perceived influence on the persuasion dimension yielded two main effects of the prestige variables and no interaction $(\mathrm{F}=0.174, \mathrm{df}=$ 1/147). A hypothetical influencer was perceived as having more influence using persuasion when described as accommodative rather than exploitative $(F=12.920$, $\mathrm{df}=1 / 147, \mathrm{p}<.001)$ and when described as wealthy rather than poor $(F=84.996, d f=1 / 147, p<.001)$.

Analysis of ratings of perceived influence on the threats dimension similarly yielded two main effects of the prestige variables and no interaction $(\mathrm{F}=0.150, \mathrm{df}=$ $1 / 147)$. An influencer was perceived as more influential when using threats when described as exploitative rather than accommodative $(\mathrm{F}=10.409, \mathrm{df}=1 / 147, \mathrm{p}<.005)$ 
Table 2

Mean Judgments of Perceived Influence for Each of the Prestige-Related Adjectives Presented Singly and in Combination

Prestige Combinations

\begin{tabular}{|c|c|c|c|c|c|c|c|c|}
\hline \multirow[b]{2}{*}{ Dimension } & \multicolumn{2}{|c|}{ Wealthy } & \multicolumn{2}{|c|}{ Poor } & \multicolumn{2}{|c|}{ Accommodative } & \multicolumn{2}{|c|}{ Exploitative } \\
\hline & Combination & Singly & Combination & Singly & Combination & Singly & Combination & Singly \\
\hline Persuasion & 14.7 & 14.7 & 8.1 & 8.3 & 12.7 & 14.5 & 10.1 & 9.7 \\
\hline Threats & 15.9 & 15.9 & 7.6 & 7.5 & 10.7 & 10.0 & 12.9 & 12.9 \\
\hline
\end{tabular}

and when described as wealthy rather than poor $(\mathrm{F}=$ $152.225, \mathrm{df}=1 / 147, \mathrm{p}<.001$ ).

The fact that no interaction was obtained between the components of prestige suggests that the intentions and capability components were combined in a linear manner by Ss in determining impressions of influence. The average rating of influence for each of the four stimulus adjectives presented singly as compared to the average rating of influence for each of the four stimulus adjectives collapsed across the other component when adjectives were presented in combination further supported the interpretation that Ss did combine the adjectives in some additive or averaging fashion. Table 2 presents the means for each stimulus adjective for each of the response dimensions when the adjectives were presented singly and in combination. As can be seen from the table, these means are almost identical, indicating that combining the adjectives added a constant effect to that generated by each adjective in isolation.

\section{DISCUSSION}

The capability and intentions variables had pronounced effects on Ss' impressions of the power of hypothetical influencers. In support of the first hypothesis, Ss perceived a wealthy individual to be more influential than a poor individual irrespective of the mode of influence employed. In support of the second and third hypotheses, an accommodative influencer was perceived as more influential than an exploitative influencer when using persuasion, but less influential when using coercion.

A simple linear model of information integration provided the best fit to the obtained data on both response dimensions (i.e., coercion and persuasion). There was no indication of a multiplicative relationship between capability and intentions in determining perceptions of an influencer. Additionally, Ss presented with the single adjective description of a wealthy threatener did not appear to infer exploitative intentions and rate the person as influential as if he had been described by both the wealthy and exploitative adjectives in combination.
It might be argued that a multiplicative relationship emerges only when an influence attempt is hedonically relevant to the perceiver, such as when the perceiver is the target of the influence attempt and it involves extremely large rewards or punishments of the perceiver. Only future research can evaluate this possibility. Alternatively, it is possible that the lower limit of the capability dimension was not really approached with the description of a poor influencer, e.g., a poor man can still threaten with a knife or possess some cache of knowledge useful for persuasion. While capability of intentions might cancel each other out when either is set at an extremely small value, information integration proceeds in a linear fashion at least within the relatively high and low levels of the variables assessed. Just as evaluative information appears to be integrated in a simple linear fashion in determining the attractiveness (cf. Anderson, 1968) or social desirability (Anderson, 1973) of a stimulus person, so information about the prestige of an individual is combined in a linear fashion in determining perceptions of social influence.

\section{REFERENCES}

Anderson, N. H. A simple model for information integration. In R. P. Abelson, E. Aronson, W. J. M cGuire, T. M. Newcomb, M. J. Rosenberg, and P. H. Tannenbaum (Eds.), Theories of cognitive consistency: A sourcebook. Chicago: Rand $\mathrm{McNally}$, 1968. Pp. 731-743.

Anderson, N. H. Functional measurement and psychophysical judgment. Psychological Review, 1970, 77, 153-170.

Anderson, N. H. Integration theory and attitude change. Psychological Review, 1971, 78, 171-206.

Anderson, N. H. Functional measurement of social desirability. Sociometry, 1973, 36, 89-98.

Asch, S. E. Forming impressions of personality. Journal of Abnormal \& Social Psychology, 1946, 41, 258-290.

McGuire, W. J. The nature of attitudes and attitude change. In G. Lindzey and E. Aronson (Eds.), The handbook of social psychology. (2nd ed.) Vol. 3. Reading, Mass: Addison-Wesley, 1969. Pp 136-314.

Pruitt, D. G. Definition of the situation as a determinant of international action. In $\mathrm{H}$. C. Kelman (Ed.), International behavior: A social-psychological analysis. New York: Holt, Rinehart \& Winston, 1965. Pp. 391-432.

Singer, J. D. Threat perception and the armament-tension dilemma. Journal of Conflict Resolution, 1958, 2, 90-105.

Tedeschi, J. T., Bonoma, T. V., \& Schlenker, B. R. Influence, decision and compliance. In J. T. Tedeschi (Ed.), The social influence processes. Chicago: Aldine, 1972. Pp. 346-418.

(Received for publication September 24, 1973.) 